Detollenaere, J., Pottelberge, A. van, Hanssens, L., Boerma, W., Greß, S., Willems, S. Patients' financially driven delay of GP visits: is it less likely to occur in stronger primary care systems? Medical Care Research and Review: 2018, 75(3), 292-311

\begin{tabular}{|l|l|}
\hline $\begin{array}{l}\text { Postprint } \\
\text { Version }\end{array}$ & 1.0 \\
\hline Journal website & $\frac{\text { http://journals.sagepub.com/doi/abs/10.1177/1077558716682170?url ver=Z39.8 }}{\underline{\text { 8-2003\&rfr id=ori\%3Arid\%3Acrossref.org\&rfr dat=cr pub\%3Dpubmed\& }}}$ \\
\hline Pubmed link & $\underline{\text { https://www.ncbi.nlm.nih.gov/pubmed/27927838 }}$ \\
\hline DOI & $10.1177 / 1077558716682170$
\end{tabular}

This is a NIVEL certified Post Print, more info at http://www.nivel.eu

\title{
Patients' Financially Driven Delay of GP Visits. Is It Less Likely to Occur in Stronger Primary Care Systems?
}

\author{
JENS DETOLLENAERE ${ }^{1}$, AMELIE VAN POTTELBERGE ${ }^{1}$, LISE HANSSENS ${ }^{1}$, WIENKE BOERMA $^{2}$, \\ STEFAN GRE $\beta^{3}$, SARA WILLEMS ${ }^{1}$ \\ ${ }^{1}$ Ghent University, Ghent, Belgium \\ ${ }^{2}$ Netherlands Institute for Health Services Research, Utrecht, Netherlands \\ ${ }^{3}$ Hochschule Fulda-University of Applied Sciences, Fulda, Germany
}

\begin{abstract}
Available evidence has suggested that strong primary care (PC) systems are associated with better outcomes. This study aims to investigate whether PC strength is specifically related to the prevalence of patients' financially driven postponement of general practitioner (GP) care. Therefore, data from a cross-sectional multicountry study in 33 countries among GPs and their patients were analyzed using multilevel logistic regression modelling. According to the results, the variation between countries in the levels of patients' postponement of seeking GP care for financial reasons was large. More than one third of these cross-country differences could be explained by characteristics of the health care system and the GP practices. In particular, PC systems with good accessibility and those systems that offer comprehensive care were associated with lower levels of financially driven delay. Consequently, we can conclude that well-organized PC systems can compensate for the negative influence of individual characteristics (socioeconomic position) on the care-seeking behaviors of patients.
\end{abstract}

\section{INTRODUCTION}

Current societal developments, such as the ageing of populations, increasing health inequities, and increasing health care expenditures, challenge the development of health care systems and drive them toward the needs of greater cost-effectiveness, responsiveness to health needs and coordinated care (Kringos, Boerma, Hutchinson, van der Zee, \& Groenewegen, 2010; Mackenbach, Meerding, \& Kunst, 2011; Van Lerberghe, 2008). Among the possible strategies to cope with these challenges, decision makers can opt for strengthening primary health care systems. A range of studies since the 1990s have provided evidence for the added value of strong primary care (PC) systems, including better health outcomes, less avoidable hospitalizations 
Detollenaere, J., Pottelberge, A. van, Hanssens, L., Boerma, W., Greß, S., Willems, S. Patients' financially driven delay of GP visits: is it less likely to occur in stronger primary care systems? Medical Care Research and Review: 2018, 75(3), 292-311

and unnecessary use of specialist services and reduced inequity in health (Andersen, 1995; Blumenthal, Mort, \& Edwards, 1995; Burström, 2002; Goddard \& Smith, 2001; Kringos et al., 2013; Whitehead \& Hanratty, 2004).

The positive influence of strong PC on the functioning of health care systems is ascribed to the core features of PC, including good access and the role of PC as the first contact for the majority of the population's curative and preventive health needs; continuity of care in settings near people's homes (Kringos et al., 2013).

Accordingly, the goal of PC systems is to provide universal and accessible care that is determined by the need for medical care rather than the patient's ability to pay (Goddard \& Smith, 2001). Barriers to health care access, for instance, in terms of postponement of care seeking, occur more often among financial and social vulnerable groups (Burström, 2002; Whitehead \& Hanratty, 2004). There are several factors that lay at the heart of care postponement by patients in need, such as language barriers, the availability of medical care in the neighborhood, health beliefs, cultural habits, and financial concerns (Andersen, 1995; Blumenthal et al., 1995; Himmelstein \& Woolhandler, 1995; Nelson, Thompson, Bland, \& Rubinson, 1999). European research has shown that financial reasons are the main reason why patients postpone medical care (Baert \& de Norre, 2009). Nonetheless, the results of this European research are dated from before the economic crisis. One could expect that the relative importance of this reason for postponement has become even more prominent as under the influence of the economic crisis, health care spending has decreased and costs of treatment have increased, posing more financial barriers for vulnerable groups. For example, as a consequence of the economic crisis in 2008, the Belgian share of households that had to postpone care because they could not afford it increased to $14 \%$ (while the share was approximately $9 \%$ before the economic crisis; Maresso et al., 2015). A PC system, however, will provide an overarching approach, especially at a time of economic crisis. Its continuing relevance lies in its values base - stressing the importance of equity, solidarity, and gender and through inclusiveness - and the objective of working toward universal coverage and consequently reducing financial barriers for vulnerable patient groups (World Health Organization [WHO], 2009). Strong PC systems provide accessible, comprehensive care in an ambulatory setting to patients in their own context on a continuous basis and coordinate the care processes of patients across the health care system (Starfield, 1994). The Primary Health Care Activity Monitor for Europe (PHAMEU) project showed that a European country's strength of PC can be measured using indicators at the structural level (i.e., governance, economic conditions, and workforce development) and at the process level (i.e., access, continuity, coordination, and comprehensiveness) in the context of the health care system (Himmelstein \& Woolhandler, 1995; Kringos et al., 2013). Governance included information about the existence of PC policies and regulations, for example, information about the equal distribution of PC providers and facilities. The availability of financial resources for PC and the population's coverage for PC services are two examples of items that were included in the economic condition indicator. Information about the health care providers, including age, training, and workload, was summarized in the workforce development indicator. The accessibility indicator contained the national and geographic service supplies and the organization of the access to practices. Conditions related to enduring doctor-patient relationships were measured in the continuity of care indicator. The coordination of care indicator contained, for 
Detollenaere, J., Pottelberge, A. van, Hanssens, L., Boerma, W., Greß, S., Willems, S. Patients' financially driven delay of GP visits: is it less likely to occur in stronger primary care systems? Medical Care Research and Review: 2018, 75(3), 292-311

example, the collaborations within PC and with secondary care, the mix of skills of the professionals, and the existence of a gatekeeping system. Finally, the scope of services offered to patients at the primary level was captured in the comprehensiveness of $\mathrm{PC}$ indicator.

The importance of a strong PC system is also acknowledged by the WHO. According to this institution, the PC system is the cornerstone of their strategy to strengthen health systems toward "Health for All" (Van Lerberghe, 2008). As aforementioned, to do so, the PC system should achieve equitable access. Therefore, we hypothesize that countries with relatively stronger PC systems are associated with lower rates of postponement compared with weaker PC systems. Strong PC systems should result in the (timely) treatment of problems before they become more severe and require specialist care or hospitalization. Moreover, among other factors, accessible PC systems are influenced by limited financial thresholds for consultations and sufficient geographical provision of care (European Commission, 2014). Keeping the aforementioned issues in mind, we expect to observe reduced financially driven postponement in health care systems with a strong focus on PC systems. The current article aims to test this hypothesis. More concretely, we answer the following research question:

Research Question 1: To what extent are strong PC systems (i.e., health care systems with a major focus on PC use) associated with lower financially driven postponement?

\section{New Contributions}

We advance the state-of-the-art of health services research by investigating the association between PC strength and financial postponement, using unique data from 31 European countries, and two non-European countries. Our study is original in which it merges two large and recent international databases. First, the PHAMEU database is the largest and most comprehensive overview of the strength of PC systems in Europe. Up to 2011, such information was either not available or outdated and incomparable across nations (Kringos et al., 2015). Second, we merged the PHAMEU database with the recent Quality and Costs of Primary Care in Europe (QUALICOPC) database. Using a multi-actor design, QUALICOPC integrates health information at different PC levels. Surveying GPs and their patients allowed the researchers to align information provided by patients and their GPs, and this was carried out in no less than 34 countries (Schäfer et al., 2011).

\section{METHOD}

\section{Data Collection}

Within the framework of the QUALICOPC study, a cross-sectional multicountry study, surveys were conducted in 31 European countries (the European Union 27 [with the exception of France], FYR Macedonia, Iceland, Norway, Switzerland, and Turkey) and 3 non-European countries as well as in Australia, Canada, and New Zealand. In each country, an average of 220 general practitioner (GP) practices were selected, except for the very small countries where the average was 80 .

Between October 2011 and December 2013, data were collected with patients in the waiting rooms of GP practices, mostly by specially trained fieldworkers and in five countries also by practice staff. Random sampling was used to select GPs in countries that have national GP registers. When a country only has regional registers, 
Detollenaere, J., Pottelberge, A. van, Hanssens, L., Boerma, W., Greß, S., Willems, S. Patients' financially driven delay of GP visits: is it less likely to occur in stronger primary care systems? Medical Care Research and Review: 2018, 75(3), 292-311

regions representing the national context were selected by random sampling (and within these regions GPs were selected in a random way). If a country only has a list of the facilities in that particular country, a random selection of this list was made (Schäfer et al., 2011). Data collection among patients in each country took place during a period of several months. The patients were recruited on different days of the week and during different times of the day. The fieldworkers consecutively invited patients (aged 18 years or older) who had just had face-to-face consultations with GPs to complete a questionnaire until 10 patients had responded. The survey consisted of two questionnaires, one about the patient's experiences and one about the patient's values. The first nine respondents completed the questionnaire about their experiences with the consultation, while the 10th respondent completed the questionnaire probing the patient's values. Additionally, one GP working in the included practice completed a questionnaire. Finally, each fieldworker completed a short questionnaire about the practice facility. A unique practice identification number enabled the linkage of GPs data to patient data and the fieldworker data to allow for multilevel analyses. In total, 7.183 GPs and 61.931 patients participated in the study. Details about the study protocol and questionnaire development are provided elsewhere (Schäfer et al., 2011; Schäfer et al., 2013).

The strength of the PC systems was obtained from the PHAMEU database (Kringos, 2012). PHAMEU is a European Union-funded project that was conducted by the Netherlands Institute for Health Services Research (NIVEL) and was cofunded by the European Commission. The project was intended to produce a database comparing various characterizing aspects of European PC systems. This database shows trends and variations in PC strength across Europe, and details knowledge and expertise relating to policy strategies conducive to strengthening PC. The development of PHAMEU consisted of four sequential steps: (1) an identification of relevant PC dimensions and features by means of a systematic literature review, (2) a selection of adequate indicators within the established PC dimensions, (3) an evaluation of the indicators by European PC experts, and (4) a pilot test of the feasibility of the PHAMEU monitor in 31 European countries. In the following paragraph, we will explain these four steps in greater depth. However, for more specific and detailed information regarding the development of the PHAMEU monitor, see Kringos (2012).

The systematic literature review by the NIVEL research team identified 85 relevant systematic reviews and original research articles on PC classification published between 2003 and 2008. Ten core dimensions that constitute a PC system were derived and related to one of the three levels in the framework created by Donabedian (1980): structure, process, and outcome. The structure level consists of (1) governance, (2) workforce development, and (3) economic conditions. The process level comprised of (1) access, (2) continuity, (3) comprehensiveness, and (4) coordination. The outcome level consists of (1) efficiency of care, (2) quality of care, and (3) equity in health (Kringos, Boerma, Hutchinson et al., 2010). In the second step of the development of PHAMEU, indicators within the 10 aforementioned dimensions were identified. First, measurable indicators were selected from the publications included in the systematic literature review of step 1. Second, additional indicators were collected from a number of international databases (such as Eurostat, the World Bank, OECD Health data, and the WHO "Health for All" database). When there were no indicators for a dimension available, the NIVEL research team 
Detollenaere, J., Pottelberge, A. van, Hanssens, L., Boerma, W., Greß, S., Willems, S. Patients' financially driven delay of GP visits: is it less likely to occur in stronger primary care systems? Medical Care Research and Review: 2018, 75(3), 292-311

developed measurable indicators. In this second step, 551 indicators for the $10 \mathrm{PC}$ dimensions were identified overall. However, one of the aims of the third step was to shorten this long list of indicators and obtain a feasible set of essential indicators, using expert evaluation. These experts consisted of members of the NIVEL research team and eight other experts from various European countries (such as researchers in family medicine, GPs, and health services researchers). The experts were asked to score each indicator on its suitability for describing and comparing European PC systems on a 4-point Likert-type scale (ranging from not useful for PC system comparison to essential for PC system comparison). In this step, 143 essential indicators used to describe 9 of the 10 dimensions (i.e., governance, workforce development, economic conditions, access, continuity, comprehensiveness, coordination, efficiency of care, and quality of care) were identified. Indicators that were selected in the "equity dimension", however, obtained a low score in the expert evaluation. The experts felt that the proposed indicators measuring equity in health were influenced by various other factors (such as social conditions in which people live and work) than just disparities in PC access and use. Therefore, no indicators of the "equity dimension" were included in the PHAMEU monitor. However, equity was integrated in several other dimensions (e.g., an indicator called "policy on equality in access" in the governance dimension and an indicator called "affordability of PC services" in the access dimension; Kringos, Boerma, Bourgueil et al., 2010). Finally, in the fourth step, all retained indicators in the PHAMEU monitor were scored by national coordinators for the 31 European countries. They used the best data available from several relevant sources, such as international databases (WHO or Organization for Economic Co-operation and Development), publications of the European Observatory on Health Systems and Policies, and national statistical databases. All sources used were registered and published in Kringos et al. (2015). Furthermore, in the appendix of the present study, we added a detailed overview of the several PC strength dimensions and explained from which features they are constructed.

\section{Measuring Access}

Access to PC was measured by asking the patients whether they had postponed a GP visit within the past 12 months (yes or no). If the patients responded yes, they were asked whether the primary reason they had postponed a GP visit was financial (yes or no, Tables 1 and 2).

\section{[TABLE 1] [TABLE 2]}

\section{Calculating PC Strength Dimensions Scores}

A score for each PC strength dimension per country was calculated using the scores of the national coordinators (supra) and by means of a two-level hierarchical latent regression model. The dependent variables in this two-level hierarchical regression model were the country's score for the indicators belonging to that dimension. In the fixed part of the model, the differences in the item averages were controlled by estimating the indicator average together with the item effects (using deviation indicator coding). In the random part, at Level 1, the differences in the items' deviations were considered controlled by modelling the item measurement errors as separate variance terms for each item. At Level 2, the effect of each country on the 
Detollenaere, J., Pottelberge, A. van, Hanssens, L., Boerma, W., Greß, S., Willems, S. Patients' financially driven delay of GP visits: is it less likely to occur in stronger primary care systems? Medical Care Research and Review: 2018, 75(3), 292-311

indicator was modelled and used to calculate the country scores. Reliability coefficients of the constructed dimension scales were acceptable and could be considered reliable (Kringos et al., 2013). Following the methodology developed by Macinko, Starfield, and Shi (2003), the data on all indicators were transformed into scores ranging from 1 (weak) to 3 (strong). The limits between weak-medium and medium-strong were determined by means of the $33 \%$ and $67 \%$ percentiles, respectively.

Statistical Analyses

First, one-way analysis of variance test statistics (with Bonferroni post hoc tests) were used to test the associations between the prevalence of financially driven postponement of GP care and the independent variables.

Additionally, due to the hierarchical structure of the data (patients [Level 1] nested in GP practices [Level 2] and these practices nested in countries [Level 3]) logistic multilevel regressions were performed. These logistic multilevel regression models were used to evaluate the importance of each level independently (i.e., patient, practice, and country) in explaining the differences in postponement of GP care (i.e., our dependent variable). In view of answering our research questions, the health care system characteristics mentioned above were added as explanatory variables at the country level.

\section{[TABLE 3]}

In the first model, only variables capturing general information about two global measures of the strength of the PC system (one for structure and one for the delivery process) are included. This model, for which the results are presented in Table 3, can be abstracted by means of the following equation:

$$
\begin{aligned}
& \operatorname{logit}\left(\pi_{i j k}\right)=\ln \left(\frac{\pi_{i j k}}{1-\pi_{i j k}}\right)=\beta_{0 j k}+\beta_{1} x_{1 k}+\beta_{2} x_{2 k}+ \\
& \beta_{\text {incomeincome }_{i j k}}+\beta_{\mathrm{GDP}} \mathrm{GDP}_{i j k}
\end{aligned}
$$

$$
\begin{gathered}
\beta_{0 j k}=\beta_{0}+v_{0 k}+u_{0 j k} \\
\operatorname{logit}\left(\pi_{i j k}\right)=\ln \left(\frac{\pi_{\mathrm{ijk}}}{1-\pi_{i j k}}\right)
\end{gathered}
$$

This equation, represents the dependent variable: postponement for financial reasons in the past 12 months by patient $i$ in GP practice $j$ of country $k$. $\beta_{0 j k}$ is the constant intercept term for all patients in a particular GP practice of a particular country. Furthermore, $x_{1 k}$ is the continuous structure variable, which is calculated as the sum of a country's scores with respect to government, economic conditions, and workforce development; $x_{2 k}$ is the continuous process variable which was calculated as the sum of a country's scores for access, continuity, coordination, and comprehensiveness. All analyses were controlled for household income of the patients and GDP per capita. Household income was categorized as "below average," "around average (reference category)," or "above average" based 
Detollenaere, J., Pottelberge, A. van, Hanssens, L., Boerma, W., Greß, S., Willems, S. Patients' financially driven delay of GP visits: is it less likely to occur in stronger primary care systems? Medical Care Research and Review: 2018, 75(3), 292-311

on the respondents' answers to the question: "Compared with the average in your country, would you say your household income is ... ?" GDP per capita was added to the multilevel regression model to control for a country's average income and economic status of the included countries. It is the sum of the gross value of purchaser's prices, added by all citizens producers in the economy plus any product taxes and minus any subsidies that are not included in the value of the products (The World Bank, 2016). Data on GDP per capita from 2013 were used, as the outcome variables were also collected in 2013. $\beta_{1}$ and $\beta_{2}$ represent the coefficients corresponding to the continuous structure and process variable, respectively. Last, $v_{0 k}$ is the error term at the country level and $u_{0 j k}$ is the error term at the GP practice level.

\section{[TABLE 4]}

In the second model (of which the results are presented in Table 4), we more closely examined the independent effects of specific indicators of both the structure and process strengths of PCs by including the seven individual dimension scores. This model can be visualized using the following equation:

$$
\begin{aligned}
& \operatorname{logit}\left(\pi_{i j k}\right)=\ln \left(\frac{\pi_{i j k}}{1-\pi_{i j k}}\right)=\beta_{0 j k}+\beta_{1} x_{1 k}+\beta_{2} x_{2 k}+\beta_{3} x_{3 k}+ \\
& \beta_{4 x_{4 k}}+\beta_{5} x_{5 k}+\beta_{6} x_{6 k}+\beta_{7} x_{7 k}+\beta_{\text {incomeincome }_{i j k}}+\beta_{\mathrm{GDP}_{\mathrm{BDP}} \mathrm{GDP}_{i j k}} \\
& \beta_{0 j k}=\beta_{0}+v_{0 k}+u_{0 j k}
\end{aligned}
$$

In the equation above,

$$
\operatorname{logit}\left(\pi_{i j k}\right)=\ln \left(\frac{\pi_{i j k}}{1-\pi_{i j k}}\right)_{\text {represents the dependent }}
$$
variable and $\beta_{0 j k}$ the constant intercept term of this second model. Moreover, $x_{1 k}$ exhibits the governance dimension, $x_{2 k}$ exhibits the workforce development dimension, $x_{3 k}$ the economic conditions, $x_{4 k}$ the access dimension, $x_{5 k}$ the continuity dimension, $x_{6 k}$ the comprehensiveness dimension, and $x_{7 k}$ the coordination dimension. As in the previous regression, this analysis is also controlled for the income of the patient and GDP per capita (in US\$). The corresponding $\beta$ s represent the related coefficients; $v_{0 k}$ is the error term at the country level and $u_{0 j k}$ is the error term at the GP practice level.

In order to benchmark the results found for financially driven postponement, we provide the reader with the same analysis, but with an alternative outcome measure, that is, postponement in general. Postponement was measured by asking patients whether they had postponed a GP visit within the past 12 months (yes or no).

Analyses were conducted in MLwiN (University of Bristol, the United Kingdom, version 2.31); first-order penalized quasi-likelihood was used as the nonlinear estimation procedure. Finally, for the null model, which is a model with only the intercept term $\beta_{0 j k}$ and no explanatory variables, we calculated the variance partition coefficient (VPC) for each level. This VPC shows us the proportion of explained 
Detollenaere, J., Pottelberge, A. van, Hanssens, L., Boerma, W., Greß, S., Willems, S. Patients' financially driven delay of GP visits: is it less likely to occur in stronger primary care systems? Medical Care Research and Review: 2018, 75(3), 292-311

variance at the three levels (country, GP practice, and patient level), and indicates whether multilevel analyses are required (if VPC at the second and third level is > 0\%; Hox, Moerbeek, \& van de Schoot, 2010).

\section{RESULTS}

\section{(Financially Driven) Postponement of GP Care}

On average, $15.0 \%$ of the respondents postponed a GP visit at least once within the past year. The countries in the upper quartile concerning general postponement rates were the following: Hungary (24.9\%), FYR Macedonia (24.6\%), Lithuania (23.0\%), Estonia (21.5\%), Poland (20.6\%), Romania (20.3\%), Ireland (18.4\%), and Spain $(18.4 \%)$. The countries with the lowest postponement rates that were thus situated in the weak quartile were the following: Portugal (11.4\%), Sweden (11.4\%), England (11.2\%), Iceland (10.5\%), Switzerland (9.5\%), Malta (8.9\%), Cyprus (8.6\%), and Turkey $(6.1 \%)$. When we focused on postponement for financial reasons, we found that an average $8.5 \%$ of the patients had postponed care for this reason. Romania (23.8\%), New Zealand (23.2\%), Bulgaria (22.8\%), Cyprus (22.4\%), Ireland (21.9\%), Slovakia (14.9\%), Australia (14.8\%), and Greece (14.7\%) had the highest financial postponement rates and were thus situated in the upper quartile. Luxembourg $(2.5 \%)$, Spain $(2.5 \%)$, the Netherlands (1.4\%), Slovenia (1.3\%), Denmark (1.2\%), England $(1.1 \%)$, and Austria (0.7\%) reported the lowest financially driven postponement rates.

The Role of Health Care System Characteristics in Financially Driven Postponement of GP Care

Bivariate analyses demonstrated significant associations $(p<.001)$ between the finically driven postponement of GP care and all of the independent variables with the exception of the continuity indicator of the process strength.

In order to answer Research Question 1 of this article, we built a multivariate multilevel regression model stepwise. In the first model (Table 3), we add first the global structure scale and subsequently the process scale.

However, we will first consider the model with no explanatory variables (null model). Using this null model, we can calculate the VPC for each level, giving us the proportion of explained variance at the different levels (i.e., country, GP practice, and patient levels). The null model revealed that the variances at the country and practice levels were $0.78(0.22)$, and $0.93(0.13)$, respectively. When we calculate the VPC of each level, ${ }^{1}$ we found that $15.52 \%$ of the differences in the postponement of GP care were situated at the country level and $18.60 \%$ at practice level.

First, the analyses reveal that compared with patients with a middle income, lowincome groups are more likely to postpone a GP visit due to financial reasons. While patients with a high income are less likely, compared with patients with a middle income, to postpone a GP visit because of financial reasons. Second, according to this first multilevel model, strength of the PC process is significantly related to financially driven postponement. No significant association between strength of the PC structure and postponement for financial reasons was found.

Subsequently, the specific indicators of both the structure and process measure of PC strength were entered step-by-step into a second multivariate multilevel model (Table 4). As in the previous model, the significant association between income and financially driven postponement stays significant in the same direction. In other 
Detollenaere, J., Pottelberge, A. van, Hanssens, L., Boerma, W., Greß, S., Willems, S. Patients' financially driven delay of GP visits: is it less likely to occur in stronger primary care systems? Medical Care Research and Review: 2018, 75(3), 292-311

words, low-income groups are more likely and high-income groups are less likely to postpone a GP visit due to financial reasons, compared with middle-income groups. As in the first model, the structural strength (i.e., governance, economic conditions, and workforce development) of PC was less relevant for explaining financially driven postponement than the strength of the strength of the process level of PC. Access and comprehensiveness were relevant process characteristics in this model. In other words, health care systems with strong foci on PC in terms of access to and comprehensiveness of care resulted in less postponement of GP care for financial reasons. Last, GDP per capita is significantly inversely associated with financially driven postponement. In other words, the higher the GDP per capita in a country, the less likely patients postpone care for financial reasons.

Benchmarking of the Results Using an Alternative Outcome Measure, That Is, Postponement in General

Multilevel modelling shows that patients with a low income are more likely to postpone GP care, compared with middle-income patients. Furthermore, according to the results presented in Table 3, no strength levels are significantly associated with postponement of care. However, when dividing these strengths levels into strength dimensions (Table 4), a significant association between continuity of PC and postponement can be observed. The negative significant effect between low-income groups and postponement of care stays significant in this model.

\section{DISCUSSION}

Policy makers all over the world are urged to strengthen their PC health care systems in response to several societal evolutions. The process of strengthening PC health care systems will improve the functioning of health care systems (Starfield, 1994). The core of PC is the provision of universal accessible care and responding to the need for medical care and not providing care according to age, gender, education, income, or ethnicity (Goddard \& Smith, 2001). Despite this goal, there are still high rates of postponement of medical care among different social groups (Burström, 2002; Whitehead \& Hanratty, 2004). Previous studies indicate the importance of individual sociodemographic characteristics in the postponement care seeking; people with low-income postpone visits to GPs more often than people in higher socioeconomic groups (Vilhjalmsson, 2005; Whitehead \& Hanratty, 2004). Some of the reasons for these postponements could include lack of time, wait-and-see, language barriers, availability (i.e., restricted opening hours), health beliefs, cultural habits, and financial problems. European research indicates that $31 \%$ of the unmet need for medical care is due to financial reasons (Baert \& de Norre, 2009). This study examined the extent to which the strength of the PC system is related to the postponement of GP care for financial reasons.

Concerning the prevalence of financially driven postponement of GP care, we found that the highest rates occurred in Cyprus, Romania, and New Zealand, and the lowest rates occurred in Austria, Denmark, and England. System characteristics (at both the national health care system and local GP levels) explained more than one third of the differences (i.e., 34.1\%) in the financially driven postponement of GP care. In other words, the organization of all different dimensions of the (primary) health care system and the GP practice can decrease patients' financial access and therefore lead them to postpone GP care. These system characteristics could also compensate for the most important influence of the individuals' characteristics on care-seeking 
Detollenaere, J., Pottelberge, A. van, Hanssens, L., Boerma, W., Greß, S., Willems, S. Patients' financially driven delay of GP visits: is it less likely to occur in stronger primary care systems? Medical Care Research and Review: 2018, 75(3), 292-311

behavior. Future research could assess in further depth the influences of system characteristics on the different operating levels and also the potential of system characteristics to compensate for the socioeconomic disadvantages of some patients. Especially noteworthy, and the most important finding of this study is, when we elaborated the roles of specific health care system characteristics, it became clear that the PC process level was associated with the financially driven postponement of GP care. Particularly in PC systems with accessible and/or comprehensive care, there was less postponement of GP care due to financial reasons. Governments of countries should focus on developing policies that reduce barriers to access to care. In line with the composition of the access indicator in the analyses, policies should, therefore, be focused on (1) national availability of PC services, (2) geographical availability, (3) accommodation of accessibility, (4) affordability, and (5) acceptability (Kringos, 2012). Last, the way PC systems address the wide variety of basic needs that exist in the community (i.e., comprehensiveness) is negatively associated with postponement for financial reasons. Consequently, policy makers could consider enhancing the comprehensiveness of their PC system by focus their policy on (1) adequate medical equipment available, (2) PC as first contact for common health problems, (3) PC for treatment and follow-up of diagnoses, (4) preventive care, (5) mother and child and reproductive care, and (6) health promotion (Kringos, 2012). This inverse association between financially driven postponement and comprehensiveness can by explained because having a broad range of services in the PC system encourages patients to present their (health) problem at the primary level of care and not at secondary care, which is less cost-effective care, and, therefore, more expensive both for society and for the individual patient. Last, the results of this article show that low-income groups are most vulnerable for both postponing GP care in general and financially driven postponement of care.

\section{Strengths and Weaknesses}

The QUALICOPC study is the first, largest (61,931 patients, 7,183 GP practices, and 34 countries) and most comprehensive database regarding PC. Its unique structure combining data from three levels (patient level, GP practice level, and country level) is a major strength of current study. The combination of the QUALICOPC data with the PHAMEU data allowed us to evaluate the associations between the structure and the performance of health care systems on different levels (Schäfer et al., 2011) to elaborate on the benefits of PC.

Although we feel that the results of the present study are important, there are some limitations that should be considered. First, a limitation of the study that is specifically relevant to care avoidance is the fact that the included patients are visitors of GP practices only. In other words, the participants had overcome some obstacles to visit their GP. Heavy avoidance of care may therefore be underrepresented. Consequently, our postponement distribution is probably biased downward. Furthermore, the data on the strengths of the PC systems were derived from the PC Monitor (PHAMEU), which is a database that was built on available data, dating from 2010. This issue could be a limitation because it may have reduced the comparability with data regarding financial postponement (that is collected between 2011 and 2013). Additionally, interviews with national experts helped find missing information, validate country results, and deliver consensus-based information (Kringos, Boerma, Bourgueil et al., 2010), which may have affected a portion of the results because the experts may have based their judgments on the 
Detollenaere, J., Pottelberge, A. van, Hanssens, L., Boerma, W., Greß, S., Willems, S. Patients' financially driven delay of GP visits: is it less likely to occur in stronger primary care systems? Medical Care Research and Review: 2018, 75(3), 292-311

objective current statuses or shortcomings of their countries' PC on the one hand or on the prospects for innovations or concerns about declines in the near future on the other hand. Furthermore, because the data on the PC systems' strength are situated at the country level, the PHAMEU data allow only between-country analyses and not within-country analyses. Subsequently, these data do not allow exploration of (or control for) the differences in access between regions in a country. Also, because there is a wide variation in the size of the included countries, the amount of heterogeneity within a country on PC may differ greatly, leading potentially to an underestimation of the variation in financial postponement explained by differences in the strength of a country's PC system. Therefore, we are in favor of future research studying the relationship between regional PC strength and financial postponement at the regional level. Finally, it is possible that other (unobserved) factors affect both dependent and independent variables. We should, therefore, be careful in interpreting causal inference.

\section{APPENDIX}

Dimensions of the primary health care activity monitor for Europe (PHAMEU) and the corresponding features (Source.Kringos, 2012).

\section{ACKNOWLEDGEMENTS}

The authors would like to thank the following partners in the QUALICOPC project for their roles throughout the study and in the coordination of the data collection: the University of Ljubljana, Hochschule Fulda, the Sant'Anna School of Advanced Studies, the NIVEL, and the National Institute for Public Health and the Environment (RIVM). Furthermore, we would like to thank the national coordinators for their cooperation and support during the fieldwork and data collection. Last, our gratitude goes to the study participants for their time and contributions to this study.

Authors' Note

Ethical approval was acquired in accordance with the legal requirements of each country. Both the GP and patient surveys were conducted anonymously.

Declaration of Conflicting Interests

The author(s) declared no potential conflicts of interest with respect to the research, authorship, and/or publication of this article.

Funding

The author(s) disclosed receipt of the following financial support for the research, authorship, and/or publication of this article: This article is based on the QUALICOPC project, which was cofunded by the European Commission under the Seventh Framework Programme (FP7/2007-2013) under grant agreement 242141.

\section{NOTES}

1.

The residual variance at the patient level was estimated to be $3.29(=\pi 2 / 3)$ using the 
Detollenaere, J., Pottelberge, A. van, Hanssens, L., Boerma, W., Greß, S., Willems, S. Patients' financially driven delay of GP visits: is it less likely to occur in stronger primary care systems? Medical Care Research and Review: 2018, 75(3), 292-311

latent variable method (Snijders \& Bosker, 1999) because in logistic multilevel analysis, the individual-level residual variance is expressed on a different scale (probability) than the higher level residual variances (logistic; Merlo et al., 2006).

\section{REFERENCES}

Andersen R. M. (1995). Revisiting the behavioral model and access to medical care: Does it matter? Journal of Health and Social Behavior, 36, 1-10.

Baert K., de Norre B. (2009). Perception of health and access to health care in the EU-25 in 2007 (Eurostat Statistics in Focus). Retrieved from

http://ec.europa.eu.proxy.library.uu.nl/eurostat/documents/3433488/5280869/KS-SF-09024-EN.PDF/f4f4f956-eafb-49f6-a52a-4a22d602433c

Blumenthal D., Mort E., Edwards J. (1995). The efficacy of primary care for vulnerable population groups. Health Services Research, 30, 253-273.

Burström B. (2002). Increasing inequalities in health care utilisation across income groups in Sweden during the 1990s? Health Policy, 62, 117-129.

Donabedian A. (1980). Explorations in quality assessment and monitoring (Vol. 1). The definition of quality and approaches to its assessment. Ann Arbor, MI: Health Administration Press. European Commission. (2014). Communication from the Commission on effective, accessible and resilient health systems. Retrieved from http://www.echamp.eu/echamp-resources/echamp-responses/c2014-07-08-echampcomment-effective-accessible-and-resilient-health-systems.pdf

Goddard M., Smith P. (2001). Equity of access to health care services: Theory and evidence from the UK. Social Science \& Medicine, 53, 1149-1162.

Himmelstein D. U., Woolhandler S. (1995). Care denied: US residents who are unable to obtain needed medical services. American Journal of Public Health, 85, 341-344.

Hox J. J., Moerbeek M., van de, Schoot R. (2010). Multilevel analysis: Techniques and applications. Retrieved from http://joophox.net/mlbook1/preview.pdf

Kringos D. S., Boerma W. G., Bourgueil Y., Cartier T., Hasvold T., Hutchinson A., . . . Tedeschi P. (2010). The European primary care monitor: Structure, process and outcome indicators. BMC Family Practice, 11(1), 81

Kringos D. S., Boerma W. G., Hutchinson A., van der Zee J., Groenewegen P. P. (2010). The breadth of primary care: A systematic literature review of its core dimensions. BMC Health Services Research, 10(1), 1.

Kringos D. S. (2012). The strength of primary care in Europe. Utrecht, Netherlands: Utrecht University.

Kringos D., Boerma W., Bourgueil Y., Cartier T., Dedeu T., Hasvold T., . . Svab I. (2013). The strength of primary care in Europe: An international comparative study. British Journal of General Practice, 63, e742-e750.

Kringos D. S., Boerma W. G., Hutchinson A., Saltman R. B. (2015). Building primary care in a changing Europe. Retrieved from

http://www.euro.who.int/_data/assets/pdf_file/0018/271170/BuildingPrimaryCareChanging Europe.pdf

Macinko J., Starfield B., Shi L. (2003). The contribution of primary care systems to health outcomes within Organization for Economic Cooperation and Development (OECD) countries, 1970-1998. Health Services Research, 38, 831-865Mackenbach J. P., Meerding W. J., Kunst A. E. (2011). Economic costs of health inequalities in the European Union. Journal of Epidemiology \& Community Health, 65, 412-419.

Maresso A., Mladovsky P., Thomson S., Sagan A., Karanikolos M., Richardson E., . . Kluge H. (2015). Economic crisis, health systems and health in Europe. Retrieved from http://www.euro.who.int/_data/assets/pdf_file/0010/279820/Web-economic-crisis-healthsystems-and-health-web.pdf?ua $=1$

Merlo J., Chaix B., Ohlsson H., Beckman A., Johnell K., Hjerpe P., . . Larsen K. (2006). A brief conceptual tutorial of multilevel analysis in social epidemiology: Using measures of clustering in multilevel logistic regression to investigate contextual phenomena. Journal of Epidemiology \& Community Health, 60, 290-297. 
Detollenaere, J., Pottelberge, A. van, Hanssens, L., Boerma, W., Greß, S., Willems, S. Patients' financially driven delay of GP visits: is it less likely to occur in stronger primary care systems? Medical Care Research and Review: 2018, 75(3), 292-311

Nelson D. E., Thompson B. L., Bland S. D., Rubinson R. (1999). Trends in perceived cost as a barrier to medical care, 1991-1996. American Journal of Public Health, 89, 1410-1413. Schäfer W. L., Boerma W. G., Kringos D. S., De Maeseneer J., Greß S., Heinemann S., . . .Vainieri M. (2011). QUALICOPC, a multi-country study evaluating quality, costs and equity in primary care. BMC Family Practice, 12(1), 115

Schäfer W.L., Boerma W.G., Kringos D.S., De Ryck E., Greß S., Heinemann S., ... Groenewegen P. (2013). Measures of quality, costs and equity in primary health care: instruments developed to analyse and compare primary health care in 35 countries. Quality in Primary Care, 21, 67-69.

Snijders T. A. B., Bosker R. J. (1999). Multilevel analysis: An introduction to basic and advanced multilevel modelling. Thousand Oaks, CA: Sage.

Starfield B. (1994). Is primary care essential? Lancet, 344, 1129-1133.

Van Lerberghe W. (2008). The World Health Report 2008: Primary health care (now more than ever). Retrieved from http://www.who.int.proxy.library.uu.nl/whr/2008/whr08 en.pdf Vilhjalmsson R. (2005). Failure to seek needed medical care: Results from a national health survey of Icelanders. Social Science \& Medicine, 61, 1320-1330.

Whitehead M., Hanratty B. (2004). Health care for rich and poor alike. In Healy J., McKee M. (Eds.), Accessing health care: Responding to diversity (pp. 28-33). Oxford, England: Oxford University Press.

The World Bank. (2016). GDP per capita. Retrieved from http://data.worldbank.org.proxy.library.uu.nl/indicator/NY.GDP.PCAP.

World Health Organization. (2009). The financial crisis and global health: Report of a highlevel consultation. Geneva, Switzerland: Author. 
Table I. National Distributions of Patients Who Postponed a GP Visit in the Past Year.

\begin{tabular}{|c|c|c|c|c|c|c|c|c|}
\hline \multirow[b]{2}{*}{ Country } & \multicolumn{4}{|c|}{$\begin{array}{l}\text { Patients who postponed a visit to the GP in the past } \\
\text { year }\end{array}$} & \multicolumn{4}{|c|}{$\begin{array}{l}\text { Patients who postponed a GP visit in the past year } \\
\text { due to financial reasons }\end{array}$} \\
\hline & $N$ & $\begin{array}{l}\text { Missing, } \\
N(\%)\end{array}$ & Yes, N(\%) & No, N (\%) & $N$ & $\begin{array}{l}\text { Missing, } \\
N(\%)\end{array}$ & Yes, N(\%) & No, N(\%) \\
\hline Austria & 1,592 & $68(4.3)$ & $208(13.1)$ & $1,316(82.7)$ & 276 & $74(26.8)$ & $2(0.7)$ & $200(72.5)$ \\
\hline Belgium & 3,670 & $62(1.7)$ & $564(15.4)$ & $3,044(82.9)$ & 626 & $90(14.4)$ & 45 (7.2) & $491(78.4)$ \\
\hline Bulgaria & 1,971 & $12(0.6)$ & $317(16.1)$ & I,642 (83.3) & 329 & $12(3.6)$ & $75(22.8)$ & $242(73.6)$ \\
\hline Cyprus & 603 & $6(1.0)$ & $52(8.6)$ & $545(90.4)$ & 58 & $6(10.3)$ & $13(22.4)$ & $39(67.2)$ \\
\hline Czech Republic & 1,980 & $9(0.5)$ & $272(13.7)$ & 1,699 (85.8) & 281 & $14(5.0)$ & $18(6.4)$ & $249(88.6)$ \\
\hline Denmark & 1,877 & $64(3.4)$ & $258(13.7)$ & $1,555(82.8)$ & 322 & $71(22.0)$ & $4(1.2)$ & $247(76.7)$ \\
\hline England & 1,296 & $38(2.9)$ & $145(11.2)$ & $1,113(85.9)$ & 184 & $40(21.7)$ & $2(1.1)$ & $142(77.2)$ \\
\hline Estonia & 1,121 & $25(2.2)$ & $241(21.5)$ & $855(76.3)$ & 266 & $20(7.5)$ & $9(3.4)$ & $237(89.1)$ \\
\hline Finland & 1,196 & $19(1.6)$ & $183(15.3)$ & $994(83.1)$ & 204 & $21(10.3)$ & $7(3.4)$ & $176(86.3)$ \\
\hline FYR Macedonia & 1,283 & $16(1.2)$ & $314(24.6)$ & $953(74.3)$ & 325 & $17(5.2)$ & $41(12.6)$ & $267(82.2)$ \\
\hline Germany & 2,117 & $8(0.4)$ & $271(12.8)$ & $1,838(86.8)$ & 279 & $13(4.7)$ & $12(4.3)$ & $254(91.0)$ \\
\hline Greece & 1,954 & $58(3.0)$ & 350 (17.9) & $1,546(79.1)$ & 456 & $69(15.1)$ & $67(14.7)$ & $320(70.2)$ \\
\hline Hungary & 1,934 & $25(1.3)$ & $482(24.9)$ & $1,427(73.8)$ & 507 & $25(4.9)$ & $65(12.8)$ & $417(822)$ \\
\hline Iceland & 761 & $50(6.6)$ & $80(10.5)$ & $631(82.9)$ & 130 & $51(39.2)$ & $5(3.8)$ & 74 (56.9) \\
\hline Ireland & 1,676 & $89(5.3)$ & $309(18.4)$ & $1,278(76.3)$ & 398 & $87(21.9)$ & $87(21.9)$ & $224(56.3)$ \\
\hline Italy & 1,947 & $49(2.5)$ & $341(17.5)$ & $1,557(80.0)$ & 395 & $64(16.2)$ & $14(3.5)$ & $317(80.3)$ \\
\hline Latvia & 1,936 & $78(4.0)$ & $311(16.1)$ & I,547 (79.9) & 389 & $47(12.1)$ & $48(12.3)$ & $294(75.6)$ \\
\hline
\end{tabular}


Table I. (continued)

\begin{tabular}{|c|c|c|c|c|c|c|c|c|}
\hline \multirow[b]{2}{*}{ Country } & \multicolumn{4}{|c|}{$\begin{array}{l}\text { Patients who postponed a visit to the GP in the past } \\
\text { year }\end{array}$} & \multicolumn{4}{|c|}{$\begin{array}{l}\text { Patients who postponed a GP visit in the past year } \\
\text { due to financial reasons }\end{array}$} \\
\hline & N & $\begin{array}{l}\text { Missing, } \\
N(\%)\end{array}$ & Yes, $N(\%)$ & No, $N(\%)$ & $N$ & $\begin{array}{l}\text { Missing, } \\
N(\%)\end{array}$ & Yes, $N(\%)$ & No, $N(\%)$ \\
\hline Lithuania & 2,008 & $15(0.7)$ & $462(23.0)$ & I,53। (76.2) & 477 & $16(3.4)$ & $16(3.4)$ & $445(93.3)$ \\
\hline Luxembourg & 707 & $23(3.3)$ & $96(13.5)$ & $588(83.2)$ & 119 & $28(23.5)$ & $3(2.5)$ & $88(73.9)$ \\
\hline Malta & 626 & $14(2.2)$ & $56(8.9)$ & $556(88.8)$ & 70 & $15(21.4)$ & $2(2.9)$ & $53(75.7)$ \\
\hline The Netherlands & 1,969 & $29(1.5)$ & $258(13.1)$ & I,682 (85.4) & 288 & $46(16.0)$ & $4(1.4)$ & $238(82.6)$ \\
\hline Norway & 1,529 & $39(2.6)$ & $179(11.7)$ & $1,3||(85.7)$ & 218 & $37(17.0)$ & $9(4.1)$ & 172 (78.9) \\
\hline Poland & 1,971 & $3(0.2)$ & $407(20.6)$ & I,56I (79.2) & 410 & $3(0.7)$ & $38(9.3)$ & $369(90.0)$ \\
\hline Portugal & $\mathrm{I}, 877$ & $46(2.5)$ & $214(11.4)$ & $1,617(86.1)$ & 261 & $44(16.9)$ & $17(6.5)$ & $200(76.6)$ \\
\hline Romania & 1,975 & $3(0.2)$ & $40 \mathrm{I}(20.3)$ & I,57| (79.5) & 404 & $2(0.5)$ & $96(23.8)$ & $306(75.7)$ \\
\hline Slovakia & 1,916 & II $(0.6)$ & $297(15.5)$ & I,608 (83.9) & 308 & II (3.6) & $46(14.9)$ & $251(81.5)$ \\
\hline Slovenia & 1,963 & $36(1.8)$ & $283(14.4)$ & $\mathrm{I}, 644(83.7)$ & 319 & $34(10.7)$ & $4(1.3)$ & $281(88.1)$ \\
\hline Spain & 3,727 & $44(1.2)$ & $687(18.4)$ & $2,996(80.4)$ & 731 & $85(11.6)$ & $18(2.5)$ & $628(85.9)$ \\
\hline Sweden & 769 & $22(2.9)$ & $88(11.4)$ & 659 (85.7) & 260 & $176(67.7)$ & $7(2.7)$ & $77(29.6)$ \\
\hline Switzerland & 1,791 & $10(0.6)$ & $170(9.5)$ & $1,611(89.9)$ & 180 & $19(10.6)$ & $7(3.9)$ & $154(85.6)$ \\
\hline Turkey & 2,605 & $0(0.0)$ & $160(6.1)$ & $2,445(93.9)$ & 160 & $5(3.1)$ & $18(11.3)$ & $137(85.6)$ \\
\hline Australia & 1,190 & $13(1.1)$ & $162(13.6)$ & $1,015(85.3)$ & 162 & $9(5.6)$ & $24(14.8)$ & $129(79.6)$ \\
\hline New Zealand & 1,150 & $24(2.1)$ & $161(14.0)$ & $965(83.9)$ & 185 & $3(1.6)$ & 43 (23.2) & $139(75.1)$ \\
\hline
\end{tabular}

Note. GP = general practitioner. 
Table 2. Bivariate Associations Between Financially Driven Postponement of GP Care and Health Care Characteristics (Structure and Process Strength), Reporting One-Way ANOVA Tests.

\begin{tabular}{|c|c|c|c|c|c|c|c|c|}
\hline & \multicolumn{8}{|c|}{ Pos } \\
\hline & \multicolumn{2}{|c|}{ Total } & \multicolumn{2}{|c|}{ No } & \multicolumn{2}{|c|}{ Yes } & \multirow[b]{2}{*}{$F$} & \multirow[b]{2}{*}{$p$} \\
\hline & $N$ & $M(S D)$ & $N$ & $M(S D)$ & $N$ & $M(S D)$ & & \\
\hline Strength PC structure & 8,451 & $6.67(0.26)$ & 7,618 & $6.68(0.27)$ & 833 & $6.57(0.23)$ & 114.18 & $<.001$ \\
\hline Governance & 8,451 & $2.43(0.11)$ & 7,618 & $2.44(0.11)$ & 833 & $2.40(0.11)$ & 66.81 & $<.001$ \\
\hline Economic conditions & 8,451 & $2.15(0.10)$ & 7,618 & $2.15(0.10)$ & 833 & $2.11(0.12)$ & 124.76 & $<.001$ \\
\hline Workforce development & 8,451 & $2.08(0.13)$ & 7,618 & $2.09(0.13)$ & 833 & $2.06(0.12)$ & 33.94 & $<.001$ \\
\hline Strength of PC process & 8,759 & $8.70(0.35)$ & 7,885 & $8.71(0.35)$ & 874 & $8.53(0.28)$ & 220.34 & $<.001$ \\
\hline Access & 8,759 & $2.25(0.14)$ & 7,885 & $2.25(0.14)$ & 874 & $2.19(0.14)$ & 195.48 & $<.001$ \\
\hline Continuity & 8,759 & $2.36(0.05)$ & 7,885 & $2.36(0.05)$ & 874 & $2.36(0.05)$ & 0.44 & .506 \\
\hline Coordination & 8,759 & $1.77(0.21)$ & 7,885 & $1.73(0.21)$ & 874 & $1.66(0.19)$ & 93.96 & $<.001$ \\
\hline Comprehensiveness & 8,759 & $2.37(0.16)$ & 7,885 & $2.37(0.16)$ & 874 & $2.33(0.17)$ & 49.80 & $<.001$ \\
\hline
\end{tabular}

Note. $\mathrm{GP}=$ general practitioner; $\mathrm{PC}=$ primary care; $\mathrm{ANOVA}=$ analy sis of variance.

All significant $(\mathrm{p}<0.05)$ are indicated in bold.

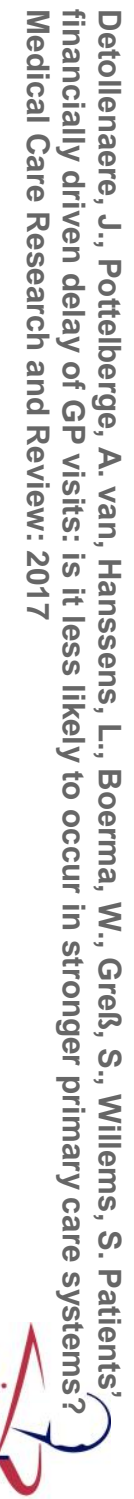


Detollenaere, J., Pottelberge, A. van, Hanssens, L., Boerma, W., Greß, S., Willems, S. Patients' financially driven delay of GP visits: is it less likely to occur in stronger primary care systems? Medical Care Research and Review: 2018, 75(3), 292-311

Table 3. Multilevel Logistic Regression of Financially Driven Postponement of GP Care (and Postponement of Care in General) on Primary Health Care Characteristics (Log Odds and Their Standard Error).

\begin{tabular}{|c|c|c|c|c|}
\hline & \multicolumn{3}{|c|}{ Financially driven postponement } & \multirow[b]{2}{*}{$\begin{array}{l}\text { Postponement } \\
\text { (in general) }\end{array}$} \\
\hline & Null model & $\begin{array}{l}\text { Strength PC } \\
\text { structure }\end{array}$ & $\begin{array}{l}\text { Strength PC } \\
\text { process }\end{array}$ & \\
\hline Strength PC structure & & $-2.63(0.96)^{* *}$ & $-1.41(1.05)$ & $-I . I 1(0.47)$ \\
\hline Strength PC process & & & $-3.21(1.47)^{*}$ & $0.60(0.68)$ \\
\hline Low income & & $0.65(0.08)^{* 6 * k}$ & $0.66(0.08)$ & $0.19(0.03)$ \\
\hline High income & & $-0.44(0.17)^{*}$ & $-0.43(0.17)^{*}$ & $0.02(0.04)$ \\
\hline GDP per capita (in US\$) & & $-0.14(0.06)^{* *}$ & $-0.10(0.05)^{*}$ & $-0.04(0.02)$ \\
\hline Intercept & $-2.60(0.16)^{* 6 * 6}$ & $3.53(2.16)$ & $7.71(2.79)^{* *}$ & $-2.79(1.26)^{*}$ \\
\hline Variance country & $0.78(0.22)^{* k *}$ & $0.52(0.16)^{* w *}$ & $0.44(0.13)^{* 1 * 4}$ & $0.11(0.03)^{3 * 4}$ \\
\hline Variance GP & $0.93(0.13)^{* * * *}$ & $0.97(0.14)^{* * k *}$ & $0.97(0.14)^{* * *}$ & $0.50(0.02)^{* * 4}$ \\
\hline$N$ & 8,723 & 8,723 & 8,723 & 55,685 \\
\hline
\end{tabular}

Note. $\mathrm{PC}=$ primary care; $\mathrm{GP}=$ general practitioner.

All significant $(p<0.05)$ are indicated in bold.

$*_{p}<.05 . *_{p}^{*}<.01 .{ }^{* *_{p}} \mathrm{p} \leq .001$. 